\title{
Foreign body giant cell reactions and ossification associated with benign melanocytic naevi
}

\author{
W F Knox, L J McWilliam, E W Benbow, R F T McMahon, N Wilkinson, R Bonshek
}

\begin{abstract}
Aims: To assess the incidence of foreign body giant cell reactions and ossification in benign/melanocytic naevi; and to examine their pathological features to gain an insight into their pathogenesis.

Methods: Intradermal $(n=185)$ and compound naevi $(n=110)$ from a routine histology service, together with 60 naevi submitted to an ophthalmic pathologist, were examined for foreign body reactions and ossification. Additional cases were identified prospectively in the course of routine reporting. The clinical and pathological features of positive cases were assessed.
\end{abstract}

Results: Foreign body reactions were identified in nine $(4.9 \%)$ intradermal and four $(3.6 \%)$ compound naevi, but in none of the naevi from around the eye. One intradermal naevus showed ossification. $A$ further 11 naevi showing foreign body reaction and five showing ossification alone were identified prospectively. The 24 naevi showing a foreign body reaction had a similar age and sex distribution to controls but were more likely to occur on the head and neck. The reaction usually occurred deep to the naevus, sometimes in relation to a hair follicle, and fragments of hair or keratin were identified in most. Osteoid or bone was present within the reaction in five. In six other naevi, all from the head and neck of women, osteoid or mature bone was present deep to the naevus in the absence of a giant cell reaction.

Conclusions: Foreign body giant cell reactions occur not uncommonly in relation to benign naevi, as a result of follicular damage, possibly due to trauma. The similar siting of foci of bone suggests that ossification occurs as a secondary phenomenon in these cases.

(F Clin Pathol 1993;46:72-74)

Table 1 Age, sex, and site of compound and intradermal naevi from two hospitals

\begin{tabular}{|c|c|c|c|c|c|}
\hline & $N=$ & Mean age & $\begin{array}{l}\text { Mean age } \\
\text { excluding } \\
\text { children } \\
<16 y\end{array}$ & $\begin{array}{l}\text { No (\%) } \\
\text { female }\end{array}$ & Predominant sites \\
\hline Compound (Hosp A) & 88 & $24 \cdot 1$ & \multirow[t]{2}{*}{$34 \cdot 7$} & $64(73)$ & \multirow{5}{*}{$\begin{array}{l}25 \% \text { Head and neck } \\
46 \% \text { Trunk } \\
19 \% \text { Head and neck } \\
62 \% \text { Trunk } \\
67 \% \text { Head and neck } \\
36 \% \text { Trunk } \\
59 \% \text { Head and neck } \\
36 \% \text { Trunk } \\
50 \% \text { Head and neck } \\
37 \% \text { Trunk }\end{array}$} \\
\hline Compound (Hosp B) & 22 & $36 \cdot 7$ & & $14(64)$ & \\
\hline Intradermal (Hosp A) & 99 & $30 \cdot 7$ & \multirow[t]{3}{*}{$34 \cdot 8$} & $77(78)$ & \\
\hline Intradermal (Hosp B) & 86 & $40 \cdot 5$ & & $47(55)$ & \\
\hline Total & 295 & $32 \cdot 0$ & & $202(68)$ & \\
\hline
\end{tabular}

Foreign body type giant cell reactions and focal ossification associated with benign melanocytic naevi have received relatively little attention in English studies, apart from brief descriptions in a few textbooks. ${ }^{1-3}$ Clinically foreign body giant cell reactions in naevi may raise the suspicion of malignant melanoma. ${ }^{4-6}$ There has been some speculation about how these reactions might come about, based on studies of their pathological features, ${ }^{4-11}$ but few systematic studies of their prevalence. The aim of this study was to assess the incidence of these phenomena and to examine their pathological features in the hope of gaining insight into their pathogenesis.

\section{Methods}

Histological sections of benign naevi were retrieved from the files of two hospital histopathology departments and screened for the presence of foreign body type reactions, epithelioid or other granulomas, and ossification; one of these hospitals has a plastic surgery department, the other does not. Additionally naevi submitted to an ophthalmic pathology service were studied. Following this retrospective review of archival material, several naevi showing foreign body reactions or ossification were identified prospectively during routine reporting and included in the study.

The following features of all naevi showing these reactions were recorded: age and sex of patient; site; type; diameter and depth of naevi; position; size and histological features of the reactions; and associated features such as fibrosis and follicular dilatation. Age, sex, and site were recorded for naevi without reactions.

\section{Results}

The initial survey included 185 intradermal and 110 compound naevi submitted by general and plastic surgeons (table 1). The hospital with a plastic surgery unit had more female patients and more lesions from the head and neck, and the average age of its patients was lower because several children were included. (The difference in proportions of intradermal and compound naevi examined in the two hospitals was a reflection of different methods of retrieval from file). In both hospitals intradermal naevi were found in slightly older patients than compound naevi; the former were more common in the head and neck, while the latter were more common on the trunk. Sixty one naevi, of which 57 were intradermal, were submitted by the eye sur- 
Table 2 Features of naevi showing associated foreign body reaction or ossification

\begin{tabular}{llll}
\hline & Foreign body reaction & \multicolumn{2}{l}{ Ossification } \\
\hline Mean age & $34 \cdot 2$ & $47 \cdot 2$ & \\
No (\%) females & $18(75 \%)$ & 6 & $(100 \%)$ \\
No (\%) head and neck & $18(75 \%)$ & 6 & $(100 \%)$ \\
Intradermal & $18(75 \%)$ & 6 & $(100 \%)$ \\
Compound & $6(25 \%)$ & $-3.9 \mathrm{~mm}(3.4-4.5 \mathrm{~mm})$ \\
Mean range diameter of naevus & $5 \cdot 2 \mathrm{~mm}(3-8 \mathrm{~mm})$ & 3.9 & $2.8 \mathrm{~mm}(2-3.5 \mathrm{~mm})$ \\
Mean depth of naevus & $2.9 \mathrm{~mm}(0.5-6 \mathrm{~mm})$ & $2.8 \mathrm{~m}$ & \\
\hline
\end{tabular}

geons: $80 \%$ of these occurred in women and the mean age was $55 \cdot 2$ years.

Altogether, nine of the $185(4.9 \%)$ intradermal naevi and four of the $110(3.6 \%)$ compound naevi in the initial survey showed a foreign body giant cell reaction and one intradermal naevus showed ossification. None of the 60 naevi from the eye hospital showed either of these phenomena. A further 11 naevi showing a foreign body type reaction, with or without focal osteoid formation, and five naevi showing ossification alone were identified prospectively.

In all, 24 naevi showed a foreign body reaction (table 2 ). These were more likely to occur on the head and neck than control naevi (foreign body naevi $75 \%$ (95\% confidence intervals 53-90\%); control naevi 50\% $(44-56 \%) ;\left(\alpha^{2}\right.$ with Yates ${ }^{7}$ correction $=4 \cdot 72$ $(\mathrm{p}<0.05))$. Eighteen were intradermal and six were compound; in most of the latter the intradermal component predominated. In eight cases the reaction was seen at the base of the naevus and in 10 it was deep to the naevus, generally within $2 \mathrm{~mm}$ of the base (fig 1 ). In the other cases the reaction occurred lateral to or within the naevus. The reactions varied in

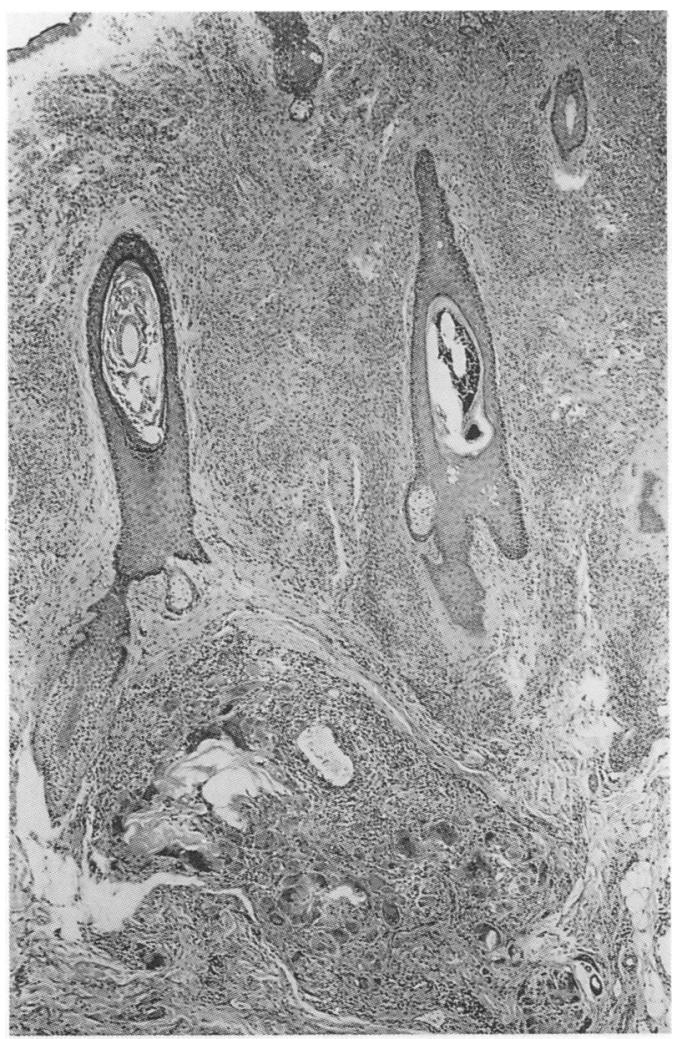

Figure 1 Foreign body giant cell reaction lying deep to a benign intradermal naevus.

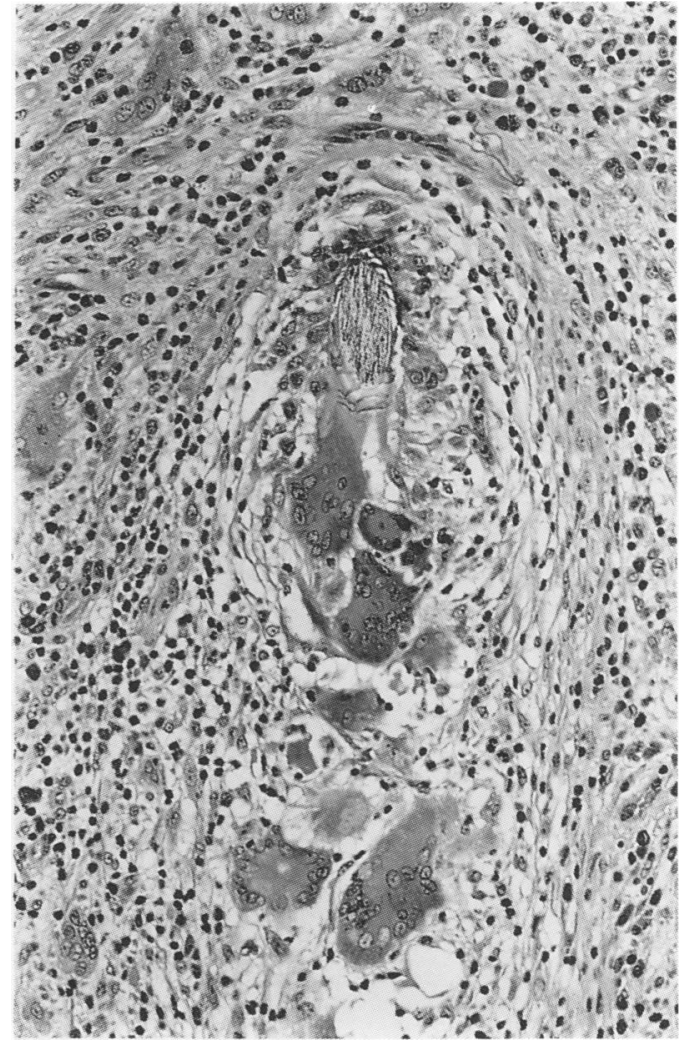

Figure 2 Foreign body granuloma containing part of a hair.

size from only one or two giant cells to aggregates of over $4 \mathrm{~mm}$ in diameter. Many occurred at the level of the pilosebaeceous follicles and some were directly related to hair follicles. Fragments of hair or keratinous material were identified in 19 of the lesions (fig 2). In some cases there were no inflammatory cells other than giant cells, while in others there was chronic or mixed inflammation including lymphocytes, plasma cells, neutrophils, eosinophils, histocytes and mast cells. In five cases foci of osteoid-like material or bone were seen within the granulomas (fig 3).

In many of the naevi there was a degree of follicular plugging or dilatation, and occasionally there was pronounced cystic dilatation of hair follicles. Fibrosis was not a predominant feature in most cases.

In six naevi, from the face or neck of five female patients, there were foci of osteoid or mature bone in the absence of a foreign body giant cell reaction (table 2). The foci of ossification were situated at the base of the naevus or up to $2 \mathrm{~mm}$ deep to the naevus, usually level with, or just deep to, hair follicles (fig 4). One 46 year old woman had two intradermal naevi on the chin, both of which showed masses of mature bone each measuring up to $1.2 \mathrm{~mm}$ in diameter, beneath the naevus. Mature fatty tissue was seen at the centre of some of these masses.

\section{Discussion}

Previous authors have suggested that foreign body type granulomas adjacent to benign intradermal naevi imply a folliculitis or rup- 


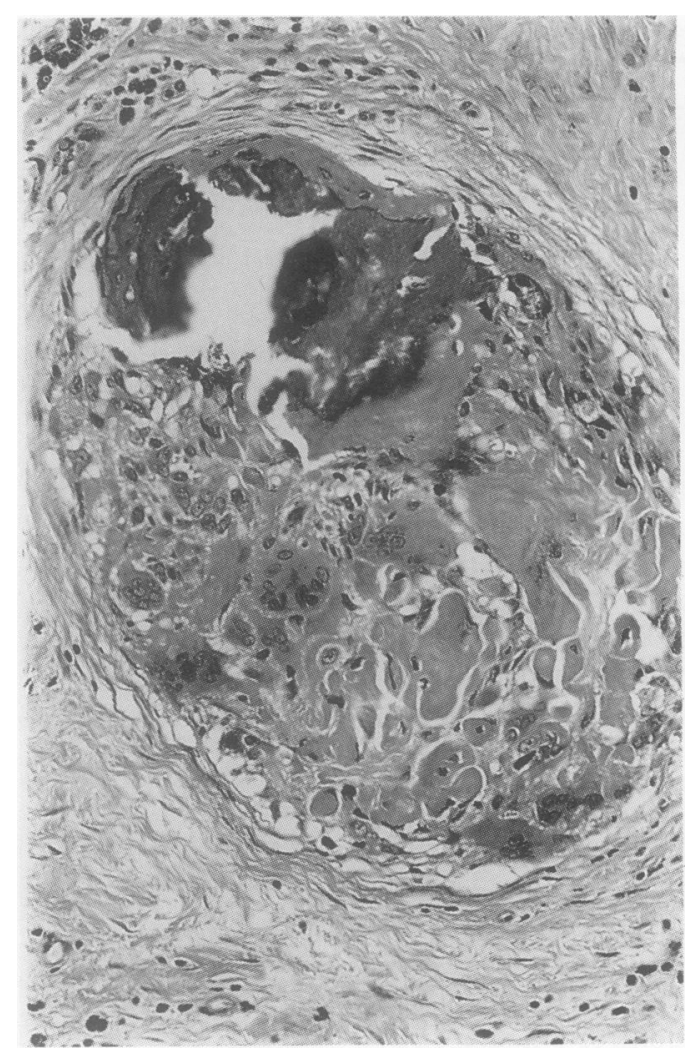

Figure 3 Early ossification occurring within a foreign body granuloma.

tured epidermal cyst. ${ }^{14-6}$ For example, Freeman and Knox found epidermal cysts, sufficiently large to permit a dual diagnosis, in $1 \%$ of benign naevi; a few of these cysts had ruptured, resulting in intense inflammation and a foreign body reaction. These workers proposed that pressure of naevus cells on a hair follicle might result in obstruction and cyst formation. Alternatively, cysts might result from strangulation of a pilosebaceous follicle by the fibrosis associated with naevus maturation. ${ }^{1}$ Currie described 10 naevi, most from the faces of women, ${ }^{6}$ with granulomas deep in the dermis, usually associated with the bases of pilosebaceous follicles within the tumour and postulated that acute infection of the follicles within the mole resulted in acute inflammation, with exposure of the hair shaft and stimulation of the foreign body reaction. It has also been suggested that the reaction is due to trauma resulting from plucking of coarse hairs growing from the surface of the mole. ${ }^{378}$

Ossification in association with naevi has been described on several occasions, virtually always in lesions from the face. ${ }^{9-11}$ In the 29 intradermal naevi with ossification reported by Roth $e t a l^{9}$ the bone was nearly always at the base or to one side of the naevus, and in five cases there was associated inflammation with foreign body giant cells.

The histological appearances of the foreign body reactions in our study support an association with follicular damage. Most occurred at the level of hair follicles and most contained hair or keratin. Fibrosis did not appear to be a noticeable feature; any follicular distortion or obstruction was likely to be due to the mass of naevus cells around the follicles. Many of the

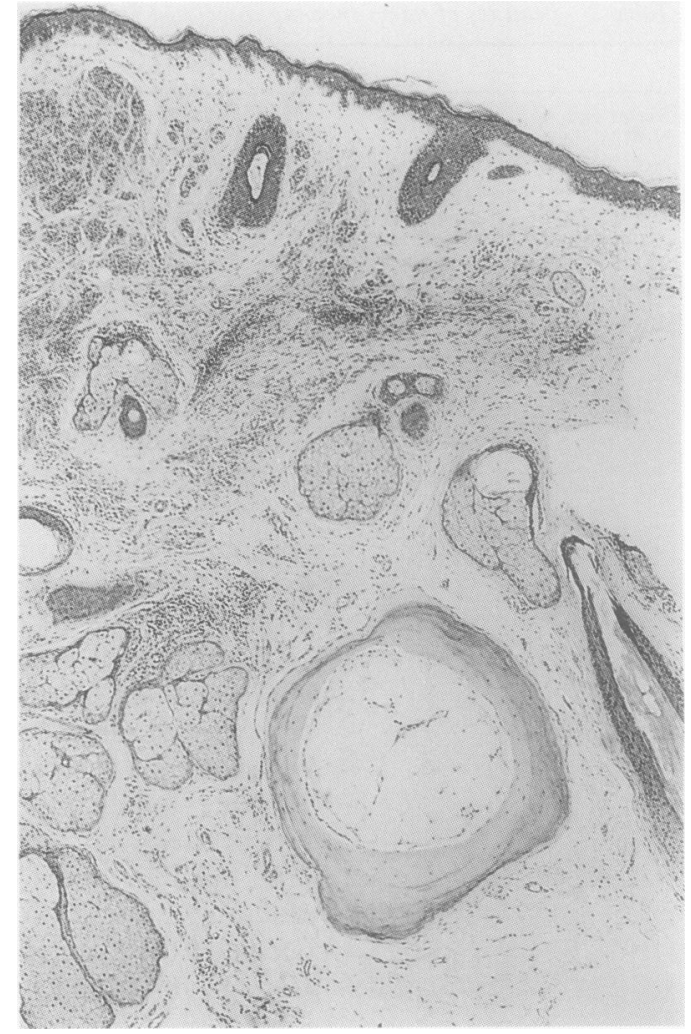

Figure 4 Focus of bone, containing fatty marrow, lying deep to a benign intradermal naevus.

naevi appeared to be very cellular and some formed polypoid masses. Although inflammation was seen in a proportion of cases, in others it was not a feature, although it is possible that infection and inflammation had occurred previously and subsided. Our findings that foreign body granulomas are more frequently associated with naevi on the face supports the hypothesis that they are caused by trauma. The similar siting of the foci of ossification to foreign body granulomas, and the occasional presence of osteoid within the latter, suggests that the metaplastic bone formation is secondary to a ruptured or damaged hair follicle and the resulting foreign body reaction. Patients who repeatedly fiddle with or pluck the hairs projecting from their facial naevi might be discouraged from doing so by the thought that this might lead to bone formation in their facial skin.

1 Milne JA. An introduction to the diagnostic histopathology of the

skin. London: Edward Arnold, 1972.
2 Lever WF, Schaumburg-Lever G. Histopathology of the skin. Philadelphia: JB Lippincott Co, 1983.

$3 \mathrm{McKee}$ PH. Pathology of the skin with clinical correlations. London: Gower Medical Publishing, 1989.

4 Weedon D. Unusual features of nevocellular naevi. f Cutan Pathol 1982;9:284-92.

5 Freeman RG, Knox JM. Epidermal cysts associated with pigmented naevi. Arch Dermatol 1962;85:72-6.

6 Currie AR. On the association of granulomas with simple cutaneous moles. Glasgow Med ₹ 1955;36:111-16.

$7 \mathrm{Haber} \mathrm{H}$. Some observations on common moles. $\mathrm{Br} f$ Dermatol 1962;74:224-8.

8 Saunders TS. Abscess formation in pigmented nevi. Report of three cases. Arch Dermatol 1957;76:189-92.

9 Roth SI, Stowell RE, Helwig EB. Cutaneous ossification. Arch Pathol 1963;76:56-66.

10 Delacretaz J, Frenk E. Zur pathogenese des osteonaevus Nanta. Hautarzt 1964;15:487-9.

11 Burgdorf W, Nasemann T. Cutaneous osteomas: a clinical and histopathologic review. Arch Derm Res 1977;260 121-35. 